\title{
Prognostic Value of D-dimer in patients with acute coronary syndrome treated by percutaneous coronary intervention: $a$ retrospective cohort study
}

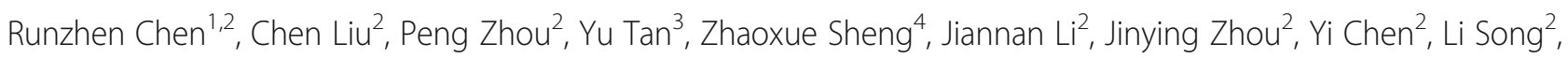
Hanjun Zhao ${ }^{1,2}$ and Hongbing $Y^{1,2^{*}}{ }^{\text {(D) }}$

\begin{abstract}
Background: Associations between D-dimer and outcomes of patients with acute coronary syndromes (ACS) remain controversial. This study aimed to investigate the prognostic value of D-dimer in ACS patients treated by percutaneous coronary intervention ( $\mathrm{PCl})$.

Methods: In this observational study, 3972 consecutive patients with ACS treated by PCI were retrospectively recruited. The X-tile program was used to determine the optimal D-dimer thresholds for risk stratifications. Cox regression with multiple adjustments was used for outcome analysis. Restricted cubic spline (RCS) analysis was performed to assess the dose-response association between D-dimer and outcomes. The C-index was calculated to evaluate the additional prognostic value of D-dimer when added to clinical risk factors and commonly used clinical risk scores, with internal validations using bootstrapping methods. The primary outcome was all-cause death.

Results: During a median follow-up of 720 days, 225 deaths occurred. Based on the thresholds generated by X-tile, ACS-PCl patients with median (420-1150 ng/mL, hazard ratio [HR]: 1.58, $95 \%$ confidence interval [Cl]: 1.14-2.20, $P=$ $0.007)$ and high ( $\geq 1150 \mathrm{ng} / \mathrm{mL}, \mathrm{HR}: 1.98,95 \% \mathrm{Cl}: 1.36-2.89, P<0.001)$ levels of D-dimer showed substantially higher risk of death compared to those with low D-dimer $(<420 \mathrm{ng} / \mathrm{mL})$. RCS analysis depicted a constant relation between D-dimer and various outcomes. The addition of D-dimer levels significantly improved risk predictions for all-cause death when combined with the fully adjusted models ( $C$-index: 0.853 vs. $0.845, P$ difference $=0.021)$, the GRACE score (C-index: 0.826 vs. $0.814, P$ difference $=0.027)$, and the TIMI score $(C$-index: 0.804 vs. $0.776, P$ difference $<$ 0.001). The predicted mortality at the median follow-up (two years) was $1.7 \%, 5.2 \%$, and $10.9 \%$ for patients with low, median, and high D-dimer, respectively, which was well matched with the observed mortality (low D-dimer group: 1.2\%, median D-dimer group: 5.2\%, and high D-dimer group: $12.6 \%$ ).

(Continued on next page)
\end{abstract}

\footnotetext{
*Correspondence: hbyanfuwai2018@163.com; hbyanfuwai@aliyun.com

${ }^{1}$ Fuwai Hospital, Chinese Academy of Medical Sciences, Shenzhen, China ${ }^{2}$ Fuwai Hospital, National Center for Cardiovascular Diseases, Peking Union Medical College, Chinese Academy of Medical Sciences, 167 Beilishi Rd, Xicheng District, 100037 Beijing, China

Full list of author information is available at the end of the article
}

(c) The Author(s). 2021 Open Access This article is licensed under a Creative Commons Attribution 4.0 International License, which permits use, sharing, adaptation, distribution and reproduction in any medium or format, as long as you give appropriate credit to the original author(s) and the source, provide a link to the Creative Commons licence, and indicate if changes were made. The images or other third party material in this article are included in the article's Creative Commons licence, unless indicated otherwise in a credit line to the material. If material is not included in the article's Creative Commons licence and your intended use is not permitted by statutory regulation or exceeds the permitted use, you will need to obtain permission directly from the copyright holder. To view a copy of this licence, visit http://creativecommons.org/licenses/by/4.0/ The Creative Commons Public Domain Dedication waiver (http://creativecommons.org/publicdomain/zero/1.0/) applies to the data made available in this article, unless otherwise stated in a credit line to the data. 
(Continued from previous page)

Conclusions: For ACS patients treated by PCI, D-dimer level was an independent predictor for adverse outcomes, and provided additional prognostic value when combined with clinical risk factors and risk scores. Risk stratifications based on D-dimer was plausible to differentiate ACS-PCl patients with higher risk of death.

Keywords: D-dimer, Acute coronary syndromes, Percutaneous coronary intervention, Prognosis, Risk stratifications

\section{Background}

D-dimer, the direct product from degradation of cross-linked fibrin, was one of the most widely used biomarkers for diagnosis and outcomes predictions of thrombotic and vascular diseases [1-6]. Recent studies show that D-dimer improves the risk predictions among patients with stable coronary heart disease treated by percutaneous coronary intervention (PCI) [3, 4]. Basically, the elevation of D-dimer reflects the activation of coagulation and fibrinolysis, which indicates a systemic prothrombotic state $[1,7]$. Evidences from intravascular imaging studies also suggest a positive linkage between D-dimer level and vulnerability of atherosclerotic plaques [8, 9]. Therefore, D-dimer could be a valuable biomarker for detecting hypercoagulation and unstable lesions, which are important pathogenesis for acute coronary events [10, 11], and might have the potential to assist risk stratifications of patients with coronary heart disease.

However, outcome predictions based on D-dimer have been seldom used in current clinical practice, as there are no clear definitions of high-risk populations. The cut-off thresholds for risk stratifications have not yet been developed or validated, as most previous studies generally divide patients according to selected percentiles $[3,4,12,13]$. It is also not clear whether the risk of adverse outcomes grow constantly along with the increase of D-dimer, since there is no study analyzing the dose-response association between D-dimer and outcomes. Moreover, the prognostic value of D-dimer remains controversial in the context of acute coronary syndrome (ACS), as previous studies report huge variation regarding hazards associated with $\mathrm{D}$-dimer elevation, and its value for improving risk predictions [1218]. Therefore, this study aimed to investigate the followings: (1) the association between D-dimer and adverse outcomes, (2) the optimal D-dimer cut-off thresholds for risk stratifications, and (3) whether Ddimer could improve the risk predictions when added to common clinical risk factors and commonly used clinical risk scores, in order to offer evidence for clinical applications of D-dimer in ACS patients.

\section{Methods}

\section{Study cohort}

This retrospective study was based on a prospective cohort in a large-volume PCI center at a national tertiary care institute (Fuwai Hospital, Beijing) specializing in cardiovascular diseases, which has enrolled all patients undergoing coronary angiography and PCI procedures (emergent or selective) from January 2010 to June 2017. ACS consisted of ST-segment elevation myocardial infarction (STEMI) and non-ST-elevation ACS (NSTEACS). Diagnoses and classifications of ACS were made according to guidelines and universal definitions up to date, including criteria of clinical presentations, typical characteristics on electrocardiography, dynamical changes of cardiac enzymes, and imaging evidence [1921]. All patients diagnosed with ACS subsequently undergoing emergent coronary angiography and PCI were included in this study. Patients were excluded if they had thrombotic diseases diagnosed during the index hospitalizations (i.e., pulmonary embolism, deep vein thrombosis, arterial thrombosis, mural thrombus, and thrombophlebitis), or no follow-up records. The study was performed in accordance with principles set forth in the Declaration of Helsinki, and was approved by the ethics committee of the institute. All patients had signed the written informed consents during hospitalization regarding the use of clinical data for the purpose of scientific research by the institute.

\section{Coronary angiography and $\mathrm{PCl}$ procedure}

Emergent coronary angiography and PCI procedures were routinely performed through radial access. Heparin $(100 \mathrm{IU} / \mathrm{kg}$ ) was routinely administered during the procedures. Blood flow of the infarct-related artery was assessed according to Thrombolysis in Myocardial Infarction (TIMI) grading system. The use of certain PCI techniques and relevant devices (e.g., stenting, balloon dilation, thrombus aspiration, intra-aortic balloon pump) were at the discretion by the operators. All patients undergoing emergent PCI were subsequently monitored in the coronary care unit.

\section{The clinical risk scores}

The calculation for the Global Registry of Acute Coronary Events (GRACE) score and the TIMI score to predict mortality has been described in details by earlier researches [22-24]. Clinical data required for calculating the risk scores were retrieved from patient medical records, including age, weight, established clinical risk factors (diabetes, hypertension, and history of angina), systolic blood pressure, heart rate, creatinine level, 
congestive heart failure, presence of cardiac arrest, elevation of cardiac enzymes, ST-segment deviation on the electrocardiogram, anterior ST elevation or left bundle branch block, and time to treatment.

\section{Laboratory measurements}

After the PCI procedure, blood samples for D-dimer tests were routinely collected via the cubital vein as soon as patients were admitted into the coronary care unit. Plasma D-dimer level was obtained using immunoassay turbidimetry (STA Compact Assay Instrument, Diagnostica Stago Inc, France). Blood samples for other biometrics tests were collected at 6 a.m. on the next morning, while cardiac enzymes were tested on a daily basis or as required by physicians in charge.

\section{Outcomes and follow-up}

The primary outcome for the current analysis was allcause death. The secondary outcomes included the followings: (1) cardiac death; (2) major adverse cardiovascular event (MACE), which was a composite of all-cause death, recurrent myocardial infarction (MI), and ischemic stroke. Patients would be routinely followed up at 1 , 6, and 12 months after discharge. The follow-up was completed independently by staffs from the information center of the institute, using standardized questionnaires through phone-call interview, and the outcome data was then transferred to the research group on a monthly basis. Follow-up was also performed during rehospitalizations and outpatient visits at the institute because of adverse events or re-examinations. For those who survived more than a year, the subsequent follow-up would be made annually. A group of physicians ( $R$. Chen, $C$. $\mathrm{Liu}$, and J. Zhou) routinely assessed the reported adverse events. In case of a dispute, a consensus was reached by discussions.

\section{Statistical analysis}

All the statistical analysis was performed using Stata 15.0 (Stata Corp, College Station, TX, USA) and R 3.6.0 ( $\mathrm{R}$ Core Team, Vienna, Austria). Categorial variables are presented as numbers (\%). Continuous variables are presented using mean \pm SD if they follow the normal distribution. Otherwise, they are presented as medians with the 25th and 75th percentiles. Multiple imputations were performed for missing values of lab test results using the mi command. The X-tile program (Rimm Lab, Yale School of Medicine) was used to find the optimal cut-off thresholds of D-dimer to differentiate patients into high, median, and low risk groups. Univariable Cox regression model was used to assess the association between Ddimer and clinical outcomes, followed by multivariable adjustments. The models were adjusted for established risk factors of ACS patients $[19,20]$, including age, sex, diabetes mellitus, hypertension, peripheral artery disease, history of coronary artery bypass graft or PCI, diagnosis of STEMI, incidence of cardiac arrest, ejection fraction, low-density lipoprotein cholesterol, high-sensitivity Creactive protein, creatinine, peak level of cardiac troponin I, culprit lesion, multivessel disease, pre- and postprocedure TIMI grade flow, door-to-balloon time, stent placements, complete revascularization before discharge, and the use of aspirin, P2Y12 inhibitors and statins. Models fully adjusted for all collected baseline variables, the GRACE score, and the TIMI score were also performed. To assess the dose-response association between D-dimer and outcomes, logarithmic D-dimer was entered into the model adjusted for all baseline variables using restrictive cubic spline (RCS), in order to avoid nonlinearity. To evaluate the additional prognostic value of D-dimer when combined with clinical risk factors and risk scores, C-index was calculated and compared as described previously [25], using bootstrapping of 1000 replications for internal validation. The calibration curve was used to analyze the agreement between model predictions and actual observations. A $P$-value $<0.05$ was considered statistically significant.

\section{Results}

\section{Patient cohort and baseline characteristics}

From January 2010 to June 2017, the institute had admitted 4151 patients who underwent emergent coronary angiography and PCI due to ACS. Among these patients, $86(2.1 \%)$ patients were diagnosed with thrombotic diseases during the index hospitalization, and 93 (2.2\%) patients did not have follow-up records of phone-call interview, outpatient visits or re-hospitalization at the institute. Finally, a total of 3972 (95.7\%) patients were included in the current analysis. The mean age of included patients was $59.0 \pm 11.9$ years, and $78.8 \%$ of the patients were male (Table 1). Overall, the level of postprocedural D-dimer was $330(220-590) \mathrm{ng} / \mathrm{mL}$ (fibrinogen-equivalent units). Patients who died during the follow-up tended to be older, female, and complicated with more comorbidities and worse cardiac function. Their D-dimer level was significantly higher than those who survived, along with substantially higher level of high-sensitivity $\mathrm{C}$-reactive protein, creatinine and cardiac troponin I. Culprit lesions of left main artery, threevessel disease and worse anterograde blood flow were more commonly seen among patients failing to survive, and they tended to receive fewer coronary stentings or oral medications, but more placements of intra-aortic balloon pump. During a median follow-up of 720 (4282054) days, there were 225 deaths (5.7\%, incidence rate [IR]: 17.6/1000-person-years [PY]), 151 cardiac deaths (3.8\%, IR: $11.8 / 1000$ PY), and 408 MACEs (10.3\%, IR: $31.9 / 1000 \mathrm{PY})$ in total. 
Table 1 Baseline characteristics of study patients stratified by the primary outcome

\begin{tabular}{|c|c|c|c|c|}
\hline & $\begin{array}{l}\text { Overall } \\
(N=3972)\end{array}$ & $\begin{array}{l}\text { Survivors } \\
(N=3747)\end{array}$ & $\begin{array}{l}\text { Non-survivors } \\
(N=225)\end{array}$ & $P$-value \\
\hline Age, years & $59.0 \pm 11.9$ & $58.4 \pm 11.8$ & $68.4 \pm 10.6$ & $<0.001$ \\
\hline Male sex, n (\%) & $3132(78.8)$ & $2993(79.9)$ & $139(61.8)$ & $<0.001$ \\
\hline Diabetes mellitus, n (\%) & $1299(32.7)$ & $1207(32.2)$ & $92(40.9)$ & 0.007 \\
\hline Hypertension, n (\%) & $2429(61.2)$ & $2262(60.4)$ & $167(74.2)$ & $<0.001$ \\
\hline Peripheral artery diseases, n (\%) & $159(4.0)$ & $141(3.8)$ & $18(8.0)$ & 0.002 \\
\hline Previous CABG or PCI, n (\%) & $583(14.7)$ & $548(14.6)$ & 35 (15.6) & 0.702 \\
\hline STEMI, n (\%) & 3467 (87.3) & $3269(87.2)$ & $198(88.0)$ & 0.741 \\
\hline Tumor diseases, n (\%) & $81(2.0)$ & $71(1.9)$ & $10(4.4)$ & 0.009 \\
\hline Liver diseases, n (\%) & $570(14.8)$ & $555(14.8)$ & $15(6.7)$ & 0.001 \\
\hline COPD, n (\%) & $32(0.8)$ & $27(0.7)$ & $5(2.2)$ & 0.014 \\
\hline \multicolumn{5}{|l|}{ Hemodynamics } \\
\hline Heart rate, bpm & $77.4 \pm 15.2$ & $77.0 \pm 14.9$ & $83.4 \pm 19.7$ & $<0.001$ \\
\hline Systolic blood pressure, $\mathrm{mmHg}$ & $124.7 \pm 18.3$ & $124.8 \pm 18.1$ & $123.0 \pm 21.9$ & 0.157 \\
\hline$E F, \%$ & $53.8 \pm 7.6$ & $54.1 \pm 7.4$ & $48.6 \pm 9.2$ & $<0.001$ \\
\hline Cardiac arrest, n (\%) & $144(3.6)$ & $125(3.3)$ & $19(8.4)$ & $<0.001$ \\
\hline \multicolumn{5}{|l|}{ Laboratory tests } \\
\hline D-dimer, ng/mL & $330(220-590)$ & $330(220-550)$ & $600(320-1240)$ & $<0.001$ \\
\hline $\mathrm{LDL}-\mathrm{C}, \mathrm{mmol} / \mathrm{L}$ & $2.7 \pm 0.9$ & $2.7 \pm 0.9$ & $2.7 \pm 0.9$ & 0.331 \\
\hline hsCRP, mg/L & $7.16(2.75-12.03)$ & $7.00(2.71-11.94)$ & $11.17(3.88-13.13)$ & $<0.001$ \\
\hline Creatinine, $\mu \mathrm{mol} / \mathrm{L}$ & $82.0 \pm 25.1$ & $81.0 \pm 22.8$ & $98.1 \pm 47.1$ & $<0.001$ \\
\hline Peak cTnl, ng/mL & $2.50(0.44-10.80)$ & $2.48(0.44-10.62)$ & $2.97(0.62-14.01)$ & 0.093 \\
\hline GRACE score & $109.7 \pm 27.7$ & $107.7 \pm 25.9$ & $142.0 \pm 35.0$ & $<0.001$ \\
\hline TIMI score & $6.3 \pm 1.8$ & $6.2 \pm 1.8$ & $8.0 \pm 2.0$ & $<0.001$ \\
\hline \multicolumn{5}{|l|}{ Findings and details of $\mathrm{PCl}$ procedures } \\
\hline \multicolumn{5}{|l|}{ Culprit lesion, n (\%) } \\
\hline Left main artery & $95(2.4)$ & $80(2.1)$ & $15(6.7)$ & $<0.001$ \\
\hline Left anterior descending artery & $1734(43.7)$ & $1632(43.6)$ & $102(45.3)$ & \\
\hline Left circumflex & $610(15.4)$ & $592(15.8)$ & $18(8.0)$ & \\
\hline Right coronary artery & $1515(38.1)$ & $1429(38.1)$ & $86(38.2)$ & \\
\hline Bypass graft & $18(0.5)$ & $14(0.4)$ & $4(1.8)$ & \\
\hline \multicolumn{5}{|l|}{ Multi-vessel disease, n (\%) } \\
\hline 1-vessel disease & $1002(25.2)$ & $966(25.8)$ & $36(16.0)$ & $<0.001$ \\
\hline 2-vessel disease & $1253(31.6)$ & $1201(32.1)$ & $52(23.1)$ & \\
\hline 3-vessel disease & $1717(43.2)$ & $1580(42.2)$ & $137(60.9)$ & \\
\hline Pre-PCI TIMI 0 flow, n (\%) & $2607(65.6)$ & $2441(65.2)$ & $166(73.8)$ & 0.008 \\
\hline Post-PCI TIMI 3 flow, n (\%) & $3822(96.2)$ & $3617(96.5)$ & $205(91.1)$ & $<0.001$ \\
\hline D2B time, mins & $128(95-202)$ & $128(95-201)$ & $125(90-219)$ & 0.342 \\
\hline Stent placements, n (\%) & $3497(88.0)$ & $3321(88.6)$ & $176(78.2)$ & $<0.001$ \\
\hline Thrombus aspiration, n (\%) & $1649(41.5)$ & $1561(41.7)$ & $88(39.1)$ & 0.451 \\
\hline IABP, n (\%) & $381(9.6)$ & $323(8.6)$ & $58(25.8)$ & $<0.001$ \\
\hline Glycoprotein Ilb/IIla inhibitor, n (\%) & $534(13.4)$ & $507(13.5)$ & $27(12.0)$ & 0.513 \\
\hline Complete revascularization & $1731(43.6)$ & $1669(44.5)$ & $62(27.6)$ & $<0.001$ \\
\hline
\end{tabular}

Medications ${ }^{a}$ 
Table 1 Baseline characteristics of study patients stratified by the primary outcome (Continued)

\begin{tabular}{|c|c|c|c|c|}
\hline & $\begin{array}{l}\text { Overall } \\
(N=3972)\end{array}$ & $\begin{array}{l}\text { Survivors } \\
(N=3747)\end{array}$ & $\begin{array}{l}\text { Non-survivors } \\
(N=225)\end{array}$ & $P$-value \\
\hline Aspirin, n (\%) & 3930 (98.9) & $3718(99.2)$ & $212(94.2)$ & $<0.001$ \\
\hline P2Y12 inhibitors, n (\%) & 3936 (99.1) & 3719 (99.3) & $217(96.4)$ & $<0.001$ \\
\hline Statins, n (\%) & 3708 (93.4) & 3507 (93.6) & 201 (89.3) & 0.013 \\
\hline
\end{tabular}

${ }^{a}$ Medication typically referred to drugs prescribed at discharge, or otherwise, drugs being used during hospitalization if patients failed to survive the hospitalization. $\mathrm{bpm}=$ beats per minutes, $\mathrm{CABG}=$ Coronary artery bypass grafting, $\mathrm{COPD}=$ chronic obstructive pulmonary diseases, $\mathrm{CTnI}=\mathrm{cardiac}$ troponin I, D2B time $=$ door-to-balloon time, $\mathrm{EF}=$ ejection fraction, GRACE score $=$ the Global Registry of Acute Coronary Events risk score, hsCRP = high sensitivity C-reactive protein, IABP = intra-aortic balloon pump, $\mathrm{LDL}-\mathrm{C}=$ low-density lipoprotein cholesterol, $\mathrm{PCl}=$ percutaneous coronary intervention, $\mathrm{STEMI}=\mathrm{ST}$-segment elevation myocardial infarction, TIMI flow = the Thrombolysis In Myocardial Infarction grade flow, TIMI score = the Thrombolysis In Myocardial Infarction risk score

\section{Associations between D-dimer and outcomes}

According to the cut-off thresholds derived from the Xtile program, $2472(62.2 \%)$ patients were classified into low D-dimer group (<420 ng/mL), 1093 (27.5\%) patients were classified into median D-dimer group (420$1150 \mathrm{ng} / \mathrm{mL})$, and $407(10.3 \%)$ patients were classified into high D-dimer group ( $\geq 1150 \mathrm{ng} / \mathrm{mL}$ ), respectively. The Kaplan-Meier analysis (Fig. 1) showed significant differences of survival among three groups of patients for both primary and secondary outcomes (all $\mathrm{P}$ log-rank $<0.001)$. Associations between D-dimer levels and various outcomes are shown in Table 2. Univariable analysis showed that higher D-dimer levels were associated with increased mortality and incidence of MACE (Table 2). D-dimer levels remained as independent predictors of adverse events after adjustments for established risk factors, all baseline variables, the GRACE score and the TIMI score. In the fully-adjusted analysis (model 2), patients with median $(420-1150 \mathrm{ng} / \mathrm{mL}$, hazard ratio [HR]: $1.58,95 \%$ confidence interval [CI]: 1.14-2.20, $P=0.007$ ) and high ( $\geq 1150 \mathrm{ng} / \mathrm{mL}$, HR: 1.98 , $95 \% \mathrm{CI}: 1.36-2.89$, $P<0.001)$ levels of D-dimer showed substantially higher risk of all-cause death, as compared to those with low level of D-dimer $(<420 \mathrm{ng} / \mathrm{mL})$. Significantly increased risk of cardiac death was also observed for patients with median (HR: 1.67, $95 \%$ CI: 1.10-2.54, $P=0.016$ ) and high (HR: 2.15, $95 \% \mathrm{CI}: 1.35-3.42, P=0.001$ ) levels of
D-dimer. Similar increases of risk were also seen for the endpoint of MACE, where the relative risk increased for $26 \%(P=0.052)$ and $37 \%(P=0.038)$ for patients with median and high levels of D-dimer, respectively. For per unit increase of logarithmic D-dimer, the HRs were 1.26 (95\% CI: $1.10-1.44, P<0.001$ ) for all-cause death, 1.25 (95\% CI: $1.06-1.48, P=0.008$ ) for cardiac death, and 1.14 (95\% CI: $1.03-1.26, P=0.013$ ) for MACE, respectively. The RCS analysis showed that the increase of Ddimer was constantly associated with higher risk of both the primary and secondary endpoint events (Fig. 2).>

\section{Improvement for risk predictions by D-dimer}

According to $\mathrm{C}$-index analyses with internal validation using bootstrapping methods, risk models established with clinical risk factors (C-index: 0.842, 95 \% CI: $0.813-$ $0.871, P<0.001$ ), all baseline variables (C-index: 0.845 , $95 \%$ CI: $0.818-0.872, P<0.001)$, the GRACE score $(C$ index: 0.814, $95 \% \mathrm{CI}: 0.780-0.848, P<0.001)$, and the TIMI score (C-index: 0.776, $95 \% \mathrm{CI}$ : $0.743-0.809, P<$ 0.001 ) all acquired favorable performance for predictions of all-cause death. However, the addition of D-dimer still brought significant increases in $\mathrm{C}$-index to the four models above (Table 3). The C-index increased by 0.009 (95\% CI: 0.001-0.016, $P=0.019$ ) for the model of established risk factors, 0.008 (95\% CI: 0.001-0.014, $P=$ $0.021)$ for the model of all baseline variables, 0.012 (95\%

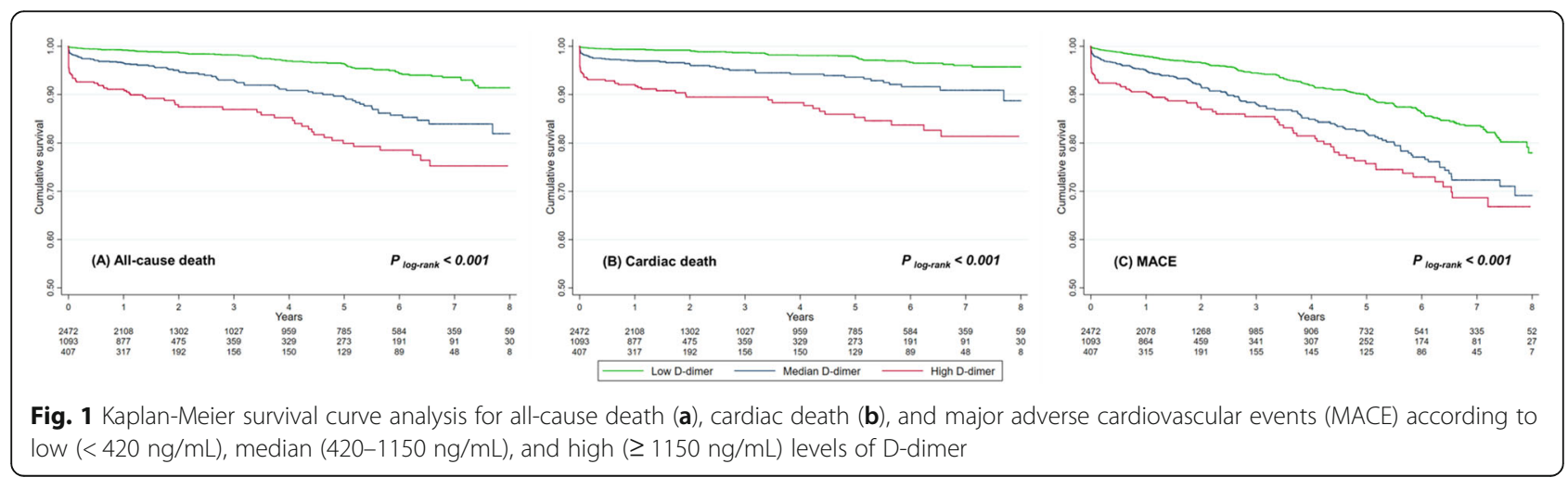


Table 2 Hazard ratio by D-dimer level for all-cause death, cardiac death, and major adverse cardiovascular events (MACE)

\begin{tabular}{|c|c|c|c|c|c|c|c|c|c|c|}
\hline & $\begin{array}{l}\text { Unadjusted } \\
\text { HR }(95 \% \mathrm{Cl})\end{array}$ & $\begin{array}{l}P \text { - } \\
\text { value }\end{array}$ & $\begin{array}{l}\text { Model } 1 \\
\text { HR }(95 \% \text { Cl) }\end{array}$ & $\begin{array}{l}P \text { - } \\
\text { value }\end{array}$ & $\begin{array}{l}\text { Model } 2 \\
\text { HR }(95 \% \text { Cl) }\end{array}$ & $\begin{array}{l}P \text { - } \\
\text { value }\end{array}$ & $\begin{array}{l}\text { Model } 3 \\
\text { HR }(95 \% \text { CI) }\end{array}$ & $\begin{array}{l}P \text { - } \\
\text { value }\end{array}$ & $\begin{array}{l}\text { Model } 4 \\
\text { HR }(95 \% \text { Cl) }\end{array}$ & $\begin{array}{l}P \text { - } \\
\text { value }\end{array}$ \\
\hline \multicolumn{11}{|l|}{ All-cause death } \\
\hline$<420 \mathrm{ng} / \mathrm{mL}$ & 1 (reference) & - & 1 (reference) & - & 1 (reference) & - & 1 (reference) & - & 1 (reference) & - \\
\hline $\begin{array}{l}420-1150 \mathrm{ng} / \\
\mathrm{mL}\end{array}$ & $2.79(2.04-3.80)$ & $<0.001$ & $1.61(1.16-2.23)$ & 0.005 & $1.58(1.14-2.20)$ & 0.007 & $1.70(1.24-2.34)$ & 0.001 & $1.81(1.32-2.49)$ & $<0.001$ \\
\hline$\geq 1150 \mathrm{ng} / \mathrm{mL}$ & $5.33(3.83-7.42)$ & $<0.001$ & $2.09(1.45-3.02)$ & $<0.001$ & $1.98(1.36-2.89)$ & $<0.001$ & $2.46(1.73-3.50)$ & $<0.001$ & $3.33(2.37-4.68)$ & $<0.001$ \\
\hline Log (D-dimer) & $1.68(1.52-1.86)$ & $<0.001$ & $1.28(1.13-1.46)$ & $<0.001$ & $1.26(1.10-1.44)$ & 0.001 & $1.36(1.21-1.54)$ & $<0.001$ & $1.51(1.46-1.67)$ & $<0.001$ \\
\hline \multicolumn{11}{|l|}{ Cardiac death } \\
\hline$<420 \mathrm{ng} / \mathrm{mL}$ & 1 (reference) & - & 1 (reference) & - & 1 (reference) & - & 1 (reference) & - & 1 (reference) & - \\
\hline $\begin{array}{l}420-1150 \mathrm{ng} / \\
\mathrm{mL}\end{array}$ & $2.91(1.97-4.31)$ & $<0.001$ & $1.17(1.10-2.52)$ & 0.016 & $1.67(1.10-2.54)$ & 0.016 & $1.67(1.12-2.50)$ & 0.012 & $1.82(1.22-2.72)$ & 0.004 \\
\hline$\geq 1150 \mathrm{ng} / \mathrm{mL}$ & $6.87(4.61-10.23)$ & $<0.001$ & $2.29(1.46-3.60)$ & $<0.001$ & $2.15(1.35-3.42)$ & 0.001 & $2.76(1.80-4.24)$ & $<0.001$ & $4.06(2.69-6.12)$ & $<0.001$ \\
\hline Log (D-dimer) & $1.77(1.57-2.00)$ & $<0.001$ & $1.28(1.09-1.50)$ & 0.003 & $1.25(1.06-1.48)$ & 0.008 & $1.38(1.19-1.60)$ & $<0.001$ & $1.58(1.37-1.82)$ & $<0.001$ \\
\hline \multicolumn{11}{|l|}{ MACE } \\
\hline$<420 \mathrm{ng} / \mathrm{mL}$ & 1 (reference) & - & 1 (reference) & - & 1 (reference) & - & 1 (reference) & - & 1 (reference) & - \\
\hline $\begin{array}{l}420-1150 \mathrm{ng} / \\
\mathrm{mL}\end{array}$ & $1.86(1.49-2.32)$ & $<0.001$ & $1.29(1.02-1.63)$ & 0.031 & $1.26(1.00-1.59)$ & 0.052 & $1.38(1.10-1.73)$ & 0.005 & $1.44(1.15-1.80)$ & 0.002 \\
\hline$\geq 1150 \mathrm{ng} / \mathrm{mL}$ & $2.53(1.94-3.29)$ & $<0.001$ & $1.44(1.08-1.92)$ & 0.013 & $1.37(1.02-1.83)$ & 0.038 & $1.60(1.23-2.11)$ & 0.001 & $1.89(1.44-2.47)$ & $<0.001$ \\
\hline Log (D-dimer) & $1.40(1.29-1.52)$ & $<0.001$ & $1.15(1.05-1.27)$ & 0.004 & $1.14(1.03-1.26)$ & 0.013 & $1.21(1.10-1.33)$ & $<0.001$ & $1.27(1.16-1.40)$ & $<0.001$ \\
\hline
\end{tabular}

CI: $0.001-0.024, P=0.027)$ for the GRACE score, and 0.028 (95\% CI: 0.013-0.043) for the TIMI score. Similar improvement was observed when logarithmic D-dimer was added to existing models as continuous variables, but the C-index was slightly lower than that of corresponding models using stratified D-dimer levels. Calibration curve analyses were performed for 180-day, oneyear, two-year, and five-year mortality, which showed good agreements of predictions and observations for all the above models including D-dimer (Supplementary Figs.1-8).

\section{Risk stratifications by D-dimer}

As risk models combining stratified D-dimer levels and all baseline variables showed the best performance, we calculated the predicted mortality at 180 days, one year, two year, and five years using this model, for which the results were compared with the actual observations (Fig. 3). The average predicted mortality at median follow-up (two years) was $1.7 \%, 5.2 \%$ and $10.9 \%$ for patients with low, median, and high levels of D-dimer, respectively, which was well matched with the observed mortality (low D-dimer group: $1.2 \%$, median D-dime group: $5.2 \%$, and high D-dimer group: $12.6 \%$ ).

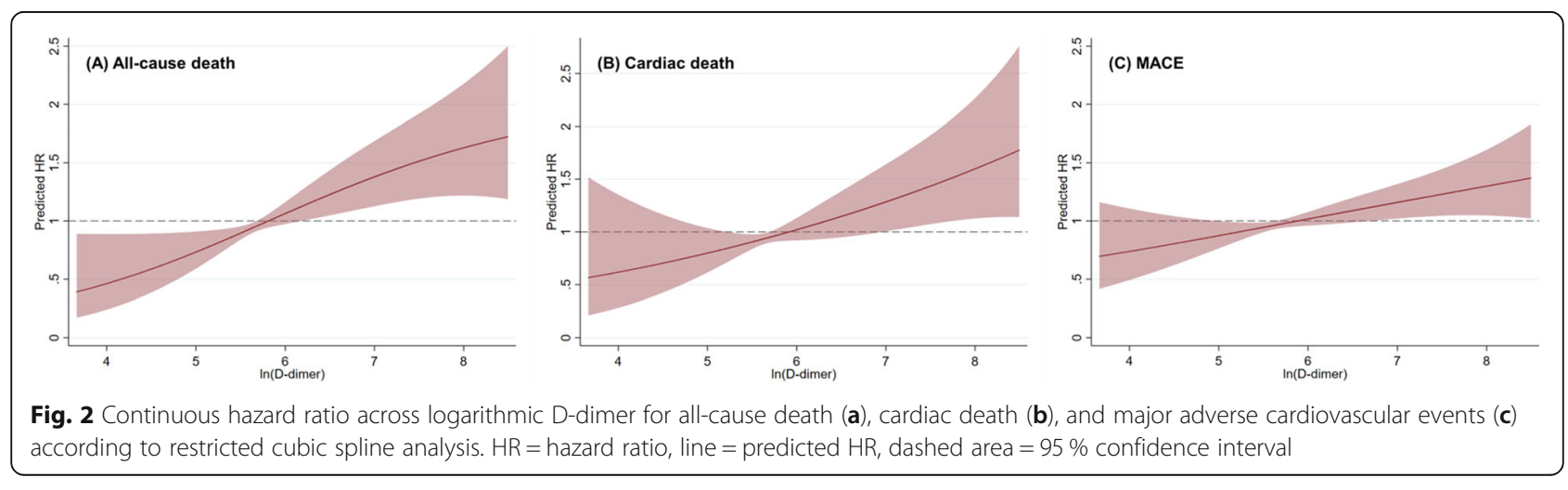


Table 3 Additional prognostic value of D-dimer for the primary outcome of all-cause death

\begin{tabular}{|c|c|c|c|c|}
\hline & Risk factors $^{a}$ & All baseline variables & GRACE score & TIMI score \\
\hline \multicolumn{5}{|c|}{ Original models } \\
\hline C-index & $0.842(0.813-0.871)$ & $0.845(0.818-0.872)$ & $0.814(0.780-0.848)$ & $0.776(0.743-0.809)$ \\
\hline \multicolumn{5}{|c|}{ Original models + D-dimer (high, median, low) } \\
\hline C-index & $0.851(0.823-0.879)$ & $0.853(0.826-0.879)$ & $0.826(0.794-0.859)$ & $0.804(0.773-0.835)$ \\
\hline$\Delta$ C-index & $0.009(0.001-0.016)$ & $0.008(0.001-0.014)$ & $0.012(0.001-0.024)$ & $0.028(0.013-0.043)$ \\
\hline$P$ difference & 0.019 & 0.021 & 0.027 & $<0.001$ \\
\hline \multicolumn{5}{|c|}{ Original models + logarithmic D-dimer } \\
\hline C-index & $0.849(0.821-0.877)$ & $0.851(0.824-0.878)$ & $0.825(0.793-0.857)$ & $0.800(0.769-0.831)$ \\
\hline$\Delta$ C-index & $0.006(0.001-0.012)$ & $0.006(0.001-0.011)$ & $0.011(0.002-0.020)$ & $0.024(0.011-0.037)$ \\
\hline$P$ difference & 0.020 & 0.021 & 0.015 & $<0.001$ \\
\hline
\end{tabular}

${ }^{a}$ Risk factors model included age, sex, hypertension, diabetes mellitus, peripheral artery diseases, history of CABG or PCl, diagnosis of STEMI, incidence of cardiac arrest, ejection fraction, LDL-C, hSCRP, creatinine, cardiac troponin I, culprit lesion, multivessel disease, pre- and post-procedure TIMI grade flow, door-to-balloon time, stent placements, complete revascularization before discharge, and the use of aspirin, P2Y12 inhibitors and statin. CABG $=$ coronary artery bypass graft, GRACE score = the Global Registry of Acute Coronary Events risk score, HR = hazard ratio, hsCRP = high-sensitivity C-reactive protein, LDL-C = low-density lipoprotein cholesterol, $\mathrm{PCl}=$ percutaneous coronary intervention, STEMI = ST-segment elevation myocardial infarction, TIMI grade flow = the Thrombolysis In Myocardial Infarction grade flow, TIMI score = the Thrombolysis In Myocardial Infarction risk score, $\Delta C$-index $=$ difference of C-index

The good correlation between predicted and observed mortality was also seen for shorter (180-day and one-year) and longer (five-year) follow-up.

\section{Discussions}

The major findings of this study are as follow. For ACS patients treated by PCI: (1) D-dimer was an independent predictor for adverse outcomes, with the optimal cut-off thresholds at $420 \mathrm{ng} / \mathrm{mL}$ and $1150 \mathrm{ng} / \mathrm{mL}$; (2) D-dimer level provided additional prognostic value when combined with established risk factors and clinical risk scores; (3) risk stratifications based on D-dimer could effectively differentiate patients with low, median, and high risk of all-cause death in both short and long term.
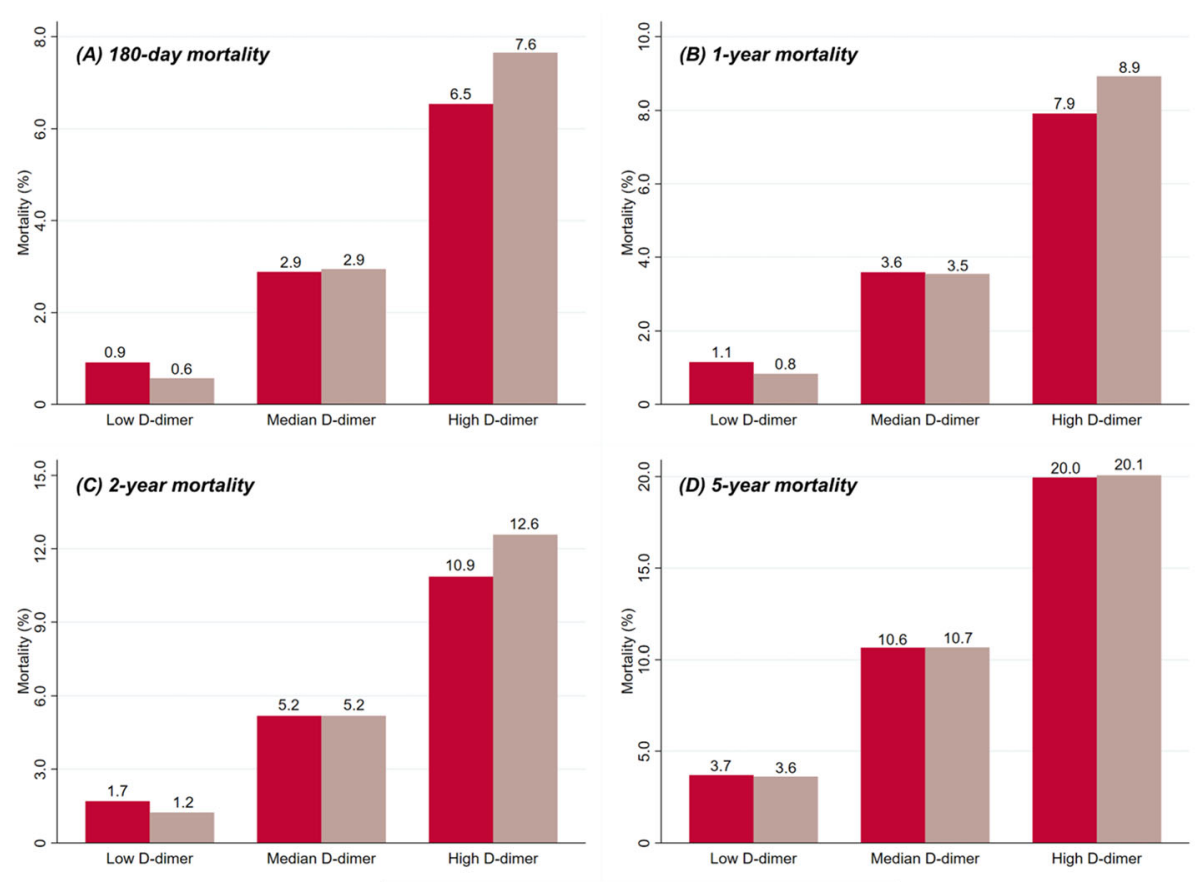

Fig. 3 Predicted and observed mortality according to low $(<420 \mathrm{ng} / \mathrm{mL})$, median $(420-1150 \mathrm{ng} / \mathrm{mL})$, and high ( $\geq 1150 \mathrm{ng} / \mathrm{mL})$ levels of D-dimer at 180 days (a), one year (b), two years (c), and five years (d) 


\section{D-dimer, mortality, and incidence of cardiovascular events}

Previous research with small sample size reported conflicting results regarding the hazard of adverse events due to elevation of D-dimer. Akgul et al. report a 10.1fold increase of 6-month mortality for STEMI patients undergoing primary PCI if D-dimer $>720 \mathrm{ng} / \mathrm{mL}$ [12]. Kikkert et al. report a 2.58-fold increase for risk of MACE if D-dimer $\geq 710 \mathrm{ng} / \mathrm{mL}$ in another STEMI cohort triaged to receive PCI, coronary artery bypass graft or medical therapy [15]. Erkol et al. suggest D-dimer loses its significance when adjusted for no-reflow phenomenon, but over $80 \%$ of the patients were excluded in the final analysis due to unavailable D-dimer measurements [14]. Therefore, prognostic value of Ddimer remained controversial, as variation in target population, treating strategies and possible selection bias do not allow a consensus. Considering that PCI and invasive strategies are widely used for the whole spectrum of ACS, the current study focused on ACS patients treated by emergent PCI. Our results suggested a stable and constant dose-response association between Ddimer and the risk for various endpoint events according to continuous variable and RCS analysis. The median Ddimer level for the whole cohort was 330 (220-590) ng/ $\mathrm{mL}$, which was quite close to that of patients with stable coronary artery disease $[3,26]$. Notably, the reported Ddimer levels of both the current and previous studies are generally lower than $500 \mathrm{ng} / \mathrm{mL}[3,4,12,14,15]$, the threshold for diagnosing deep vein thrombosis, which means that the thrombus burden within the coronary artery poses limited impacts on the systemic D-dimer level in the context of ACS. However, the risk of adverse events has already begun to increase at such low levels of D-dimer. In a research by Simes et al., the risk of allcause death increases for $59 \%$ in coronary heart disease patients with D-dimer higher than $273 \mathrm{ng} / \mathrm{mL}$ [4]. The current results showed that relative risk for all-cause death increased for 58 and $98 \%$ for patients with median (420-1150 ng/mL) and high level ( $\geq 1150 \mathrm{ng} / \mathrm{mL})$ of Ddimer, respectively, suggesting that the risk of death was elevated even though the absolute value of D-dimer was below the traditional threshold. Similar findings were observed for other secondary endpoints, which affirmed the associations between outcomes and D-dimer. Based on these findings, D-dimer was more of a reflection for the systemic prothrombotic states, which therefore predisposed ACS-PCI patients for long-term adverse events. Moreover, the association between D-dimer and outcomes remained stable after adjustment for various risk factors, including antegrade blood flow. This suggested that the linkage between adverse outcomes and D-dimer elevation was not completely mediated by the failure of reperfusion. In sum, our findings supported an independent association between D-dimer and adverse events. To our knowledge, the current study acquired the largest sample size of its kind, and was also the first to depict a dose-response association between D-dimer and various outcomes.

\section{Additional prognostic insight from D-dimer level}

Although there have been many studies suggesting a linkage between fibrinolytic components and adverse events, D-dimer is generally considered to be unspecific, and not included for the risk stratification in routine clinical practice [1, 5-7]. Meanwhile, few studies have evaluated prognostic value of $\mathrm{D}$-dimer when incorporated to commonly used risk tools for ACS patients. The current study showed that the addition of D-dimer levels (both as continuous and categorial variables) improved the accuracy of risk predictions for all-cause death. D-dimer not only improved the $\mathrm{C}$-index for models of traditional risk factors, but also the clinical risk scores. Because D-dimer remained an independent risk factor when adjusted for various clinical characteristics, D-dimer might provide information beyond demographics, comorbidities, and hemodynamics. The interaction between coagulation system and blood vessels is one of the major interpretations. Recent studies show D-dimer and fibrin degradation products are associated to unstable features of coronary plaques (e.g., greater plaque burden, larger area of necrotic core or calcification, and less fibrotic components) $[8,9]$. Activities and exposure of these sub-endothelial contents could directly activate the coagulation cascade [27-30], which constitutes a prothrombotic and inflammatory state leading to restenosis and ischemia [11, 31, 32]. Moreover, D-dimer has been shown to associate with various complications after ACS, like no-reflow and heart failure, which could be attributed to pre-existing massive thrombus within the coronary artery, multifocal vessel wall-related fibrin formation, and a systemic prothrombotic state [16, 33, 34]. Therefore, the level of D-dimer reflected the collective prognostic impacts from the activation of the coagulation system. As current risk models for ACS patients (e.g., GRACE score, TIMI score) generally predict outcomes based on clinical characteristics and hemodynamics $[22,24]$, the addition of D-dimer might have backed up these models by providing extra information on prothrombotic tendency and vulnerable lesions. In case of Ddimer elevation, the need of more intensive revascularization and antithrombotic treatments should be carefully considered, in order to achieve long-term coronary patency and low risk of recurrent ischemia.

\section{Clinical applications of D-dimer}

Although D-dimer level has been reported to correlate with outcomes, the thresholds to define the high-risk population is so far unclear and not validated $[4,8,12-$ 
15, 17]. Therefore, D-dimer is seldom used in clinical practice to assess thrombotic risk, although it is one of the most easily accessed biomarkers for thrombosis. Considering the constant does-response association between $\mathrm{D}$-dimer and outcomes, we used the X-tile program to look for the optimal cut points, and found that the thresholds of $420 \mathrm{ng} / \mathrm{mL}$ and $1150 \mathrm{ng} / \mathrm{mL}$ could effectively differentiate patients with low, median, and high risk of all-cause death. Stepwise increase of mortality was observed for both the predictions and observations, which showed favorable accuracy and correlation. This simple and clear risk stratification based on Ddimer level could have the potential to prompt for more tailored risk stratifications and treatments. For patients with high D-dimer ( $\geq 1150 \mathrm{ng} / \mathrm{mL})$, nearly one in ten patients died within two years, while over $20 \%$ of patients died within five years, indicating the unmet need of risk factors control and treatments. For patients of this kind, more intensive antithrombotic medications are reasonable choices to reduce the risk of stent thrombosis and recurrent ischemia [35, 36], including the use of more potent P2Y12 inhibitors and low dose of oral anticoagulants. More intensive revascularizations (e.g., complete revascularization) should be considered to further lower the risk of death and ischemia [37]. For patients with median level of D-dimer (420-1150 ng/mL), the intermediate outcomes also suggested a possible need for more intensive treatments, but further examinations and evaluations should be performed to validate whether there are strong indications. In this scenario, intravascular imaging examinations should be considered for assessing the stability of culprit and non-culprit arteries, which might help decision making on revascularization strategies $[8,9]$. P2Y12 gene tests would be beneficial to further differentiate non-responders for clopidogrel, and prompt the switch for more potent P2Y12 inhibitors to further lower the risk of ischemia [38]. Other risk factors (e.g., hypertension, diabetes, lifestyles) should also be reviewed to see whether there are neglected causes to drive up the level of D-dimer in this intermediate group of patients [39-41]. For patients with low D-dimer (< $420 \mathrm{ng} / \mathrm{mL}$ ), the one-year mortality was about $1 \%$, suggesting a generally low risk profile, for which routine care would be adequate to assure a favorable outcome. With a constant association between D-dimer and outcomes, physicians might also consider referring to the dynamic changes of D-dimer, to see whether the current treatments are effective in lowering the thrombotic risk, and quantitatively evaluate how much risk reduction the medication has brought to patients.

\section{Limitations}

The general limitations of this study are as follow. Firstly, patients in this study were retrospectively recruited. Although D-dimer was measured prospectively, residual confounding could exist, and the causality between elevation of D-dimer and outcomes could not be fully defined. Secondly, this observational study was accomplished in a single institute, and external validation was not performed due to limited resources of data. Despite the large sample size and internal validation, extrapolations of conclusions from the current study might require further validation.

\section{Conclusions}

D-dimer was an independent predictor of adverse outcomes for ACS patients treated by PCI. When combined with clinical risk factors, the GRACE score, and the TIMI score, D-dimer significantly improved risk predictions for mortality. Risk stratifications based on D-dimer was feasible to differentiate patients with higher risk of death in both short and long term, which could assist decision making of treating strategies.

\section{Abbreviations}

PCl: percutaneous coronary intervention; ACS: acute coronary syndrome; GRACE score: the Global Registry of Acute Coronary Events risk score; TIMI score: the Thrombolysis in Myocardial Infarction risk score; STEMI: STsegment elevation myocardial infarction; NSTE-ACS: non-ST-elevation acute coronary syndrome; RCS: restricted cubic spline

\section{Supplementary information}

The online version contains supplementary material available at https://doi. org/10.1186/s12959-021-00281-y.

Additional file 1 Fig. S1. Calibration curves for Cox regression models including D-dimer levels (high, median, and low) for all-cause mortality at 180 days. Fig. S2. Calibration curves for Cox regression models including D-dimer levels (high, median, and low) for all-cause mortality at 1 year. Fig. S3. Calibration curves for Cox regression models including D-dimer levels (high, median, and low) for all-cause mortality at 2 years. Fig. S4. Calibration curves for Cox regression models including D-dimer levels (high, median, and low) for all-cause mortality at 5 years. Fig. S5. Calibration curves for Cox regression models including D-dimer levels (logarithmic) for all-cause mortality at 180 days. Fig. S6. Calibration curves for Cox regression models including D-dimer levels (logarithmic) for all-cause mortality at 1 year. Fig. S7. Calibration curves for Cox regression models including D-dimer levels (logarithmic) for all-cause mortality at 2 years.

Fig. S8. Calibration curves for Cox regression models including D-dimer levels (logarithmic) for all-cause mortality at 5 years.

\footnotetext{
Authors' contributions

Conceptualization, R. C., C. L. and H. Y.; Data curation, R. C., C. L., P. Z., Y. T., Z. S., J. L., J. Z., Y. C., L. S., H. Z. and H. Y.; Formal analysis, R. C.; Funding acquisition, H. Y.; Methodology, R. C., Y. T. and Z. S.; Resources, R. C., C. L., P. Z., Y. T., Z. S., J. L., J. Z., Y. C., L. S. and H. Z.; Supervision, H. Z. and H. Y.; Writing - original draft, R.C.; Writing - review \& editing, R.C., C. L., P. Z., Y. T., Z. S., J. L., J. Z., Y. C., L. S., H. Z. and H. Y. All authors have read and agreed to the published version of the manuscript. The author(s) read and approved the final manuscript.
}

\section{Funding}

This study was supported by the Chinese Academy of Medical Sciences Innovation Fund for Medical Sciences (2016-12M-1-009), National Natural Science Foundation of China (81970308), and the Fund of "Sanming" Project of Medicine in Shenzhen (SZSM201911017). 


\section{Availability of data and materials}

The data used to support the findings of this study are available from the corresponding author upon request, but not publicly available, as the institution (Fuwai Hospital) requires all outer accesses to clinical data of patients to be applicated and processed in a case-by-case manner.

\section{Declarations}

\section{Ethics approval and consent to participate}

The study was performed in accordance with principles set forth in the Declaration of Helsinki, and was approved by the ethics committee of the institute. All patients had signed the written informed consents during hospitalization regarding the use of clinical data for the purpose of scientific research by the institute.

\section{Consent for publication}

Not applicable.

\section{Competing interest}

The authors declared that they have no competing interests.

\section{Author details}

${ }^{1}$ Fuwai Hospital, Chinese Academy of Medical Sciences, Shenzhen, China. ${ }^{2}$ Fuwai Hospital, National Center for Cardiovascular Diseases, Peking Union Medical College, Chinese Academy of Medical Sciences, 167 Beilishi Rd, Xicheng District, 100037 Beijing, China. ${ }^{3}$ Xiamen Cardiovascular Hospital, Xiamen University, Xiamen, China. ${ }^{4}$ China-Japan Friendship Hospital, Beijing, China.

Received: 21 January 2021 Accepted: 14 April 2021

Published online: 07 May 2021

\section{References}

1. Weitz JI, Fredenburgh JC, Eikelboom JW. A test in context: D-dimer. J Am Coll Cardiol. 2017:70(19):2411-20.

2. Tritschler T, Kraaijpoel N, Le Gal G, Wells PS. Venous thromboembolism: advances in diagnosis and treatment. JAMA. 2018;320(15):1583-94.

3. Naruse H, Ishii J, Takahashi H, Kitagawa F, Okuyama R, Kawai H, Muramatsu T, Harada M, Yamada A, Motoyama S, et al. Prognostic value of combination of plasma D-dimer concentration and estimated glomerular filtration rate in predicting long-term mortality of patients with stable coronary artery disease. Circ J. 2017;81(10):1506-13.

4. Simes J, Robledo KP, White HD, Espinoza D, Stewart RA, Sullivan DR, Zeller T, Hague W, Nestel PJ, Glasziou PP, et al. D-dimer predicts long-term causespecific mortality, cardiovascular events, and cancer in patients with stable coronary heart disease. Circulation. 2018;138(7):712-23.

5. Kyrle PA, Eichinger S. D-Dimer for long-term risk prediction in patients after acute coronary syndrome. Circulation. 2018;138(7):724-6.

6. Soomro AY, Guerchicoff A, Nichols DJ, Suleman J, Dangas GD. The current role and future prospects of D-dimer biomarker. Eur Heart J Cardiovasc Pharmacother. 2016;2(3):175-84.

7. Gorog DA. Prognostic value of plasma fibrinolysis activation markers in cardiovascular disease. J Am Coll Cardiol. 2010;55(24):2701-9.

8. Corban MT, Hung OY, Mekonnen G, Eshtehardi P, Eapen DJ, RasoulArzrumly E, Al Kassem H, Manocha P, Ko YA, Sperling LS, et al. Elevated levels of serum fibrin and fibrinogen degradation products are independent predictors of larger coronary plaques and greater plaque necrotic core. Circ J. 2016:80(4):931-7.

9. Kothari H, Nguyen AT, Yang X, Hisada Y, Tsimikas S, Mackman N, Taylor A, McNamara CA. Association of D-dimer with plaque characteristics and plasma biomarkers of oxidation-specific epitopes in stable subjects with coronary artery disease. J Cardiovasc Transl Res. 2018;11(3):221-9.

10. Crea F, Libby P. Acute coronary syndromes. Circulation. 2017;136(12):1155-66

11. Tomaniak M, Katagiri $Y$, Modolo R, Silva R, Khamis RY, Bourantas CV, Torii R, Wentzel JJ, Gijsen FJH, van Soest G, et al. Vulnerable plaques and patients: state-of-the-art. Eur Heart J. 2020;41(31):2997-3004. https://doi.org/10.1093/ eurheartj/ehaa227.

12. Akgul O, Uyarel H, Pusuroglu H, Gul M, Isiksacan $N$, Turen S, Erturk M, Surgit $\mathrm{O}$, Cetin M, Bulut U, et al. Predictive value of elevated D-dimer in patients undergoing primary angioplasty for ST elevation myocardial infarction. Blood Coagul Fibrinolysis. 2013;24(7):704-10.
13. Tello-Montoliu A, Marin F, Roldan V, Mainar L, Lopez MT, Sogorb F, Vicente V, Lip GY. A multimarker risk stratification approach to non-ST elevation acute coronary syndrome: implications of troponin T, CRP, NT pro-BNP and fibrin D-dimer levels. J Intern Med. 2007;262(6):651-8.

14. Erkol A, Oduncu V, Turan B, Kilicgedik A, Sirma D, Gozubuyuk G, Karabay CY, Guler A, Dundar C, Tigen K, et al. The value of plasma D-dimer level on admission in predicting no-reflow after primary percutaneous coronary intervention and long-term prognosis in patients with acute ST segment elevation myocardial infarction. J Thromb Thrombolys. 2014;38(3):339-47.

15. Kikkert WJ, Claessen BE, Stone GW, Mehran R, Witzenbichler B, Brodie BR, Wohrle J, Witkowski A, Guagliumi G, Zmudka K, et al. D-dimer levels predict ischemic and hemorrhagic outcomes after acute myocardial infarction: a HORIZONS-AMI biomarker substudy. J Thromb Thrombolys. 2014;37(2):155-64.

16. Sarli B, Akpek M, Baktir AO, Sahin O, Saglam H, Arinc H, Odabasi H, Dogan S, Kurtul S, Dogan Y, et al. Impact of D-dimer level on postinterventional coronary flow and in-hospital MACE in ST-segment elevation myocardial infarction. Herz. 2015:40(3):507-13.

17. Mjelva OR, Ponitz V, Brugger-Andersen T, Grundt H, Staines H, Nilsen DW. Long-term prognostic utility of pentraxin 3 and D-dimer as compared to highsensitivity C-reactive protein and B-type natriuretic peptide in suspected acute coronary syndrome. Eur J Prev Cardiol. 2016;23(11):1130-40.

18. Pineda J, Marin F, Marco P, Roldan V, Valencia J, Ruiz-Nodar JM, Romero DH, Sogorb F, Lip GY. The prognostic value of biomarkers after a premature myocardial infarction. Int J Cardiol. 2010;143(3):249-54.

19. Ibanez B, James $S$, Agewall $S$, Antunes MJ, Bucciarelli-Ducci C, Bueno H, Caforio ALP, Crea F, Goudevenos JA, Halvorsen S, et al. 2017 ESC Guidelines for the management of acute myocardial infarction in patients presenting with ST-segment elevation: The Task Force for the management of acute myocardial infarction in patients presenting with ST-segment elevation of the European Society of Cardiology (ESC). Eur Heart J. 2018;39(2):119-77.

20. Roffi M, Patrono C, Collet JP, Mueller C, Valgimigli M, Andreotti F, Bax JJ, Borger MA, Brotons C, Chew DP, et al. 2015 ESC Guidelines for the management of acute coronary syndromes in patients presenting without persistent STsegment elevation: Task Force for the Management of Acute Coronary Syndromes in Patients Presenting without Persistent ST-Segment Elevation of the European Society of Cardiology (ESC). Eur Heart J. 2016;37(3):267-315.

21. Thygesen K, Alpert JS, Jaffe AS, Chaitman BR, Bax JJ, Morrow DA, White HD, Group ESCSD. Fourth universal definition of myocardial infarction (2018). Eur Heart J. 2019;40(3):237-69.

22. Eagle KA, Lim MJ, Dabbous OH, Pieper KS, Goldberg RJ, Van de Werf F, Goodman SG, Granger CB, Steg PG, Gore JM, et al. A validated prediction model for all forms of acute coronary syndrome: estimating the risk of 6-month postdischarge death in an international registry. JAMA. 2004;291(22):2727-33.

23. Fox KA, Dabbous OH, Goldberg RJ, Pieper KS, Eagle KA, Van de Werf F, Avezum A, Goodman SG, Flather MD, Anderson FA Jr, et al. Prediction of risk of death and myocardial infarction in the six months after presentation with acute coronary syndrome: prospective multinational observational study (GRACE). BMJ. 2006;333(7578):1091.

24. Morrow DA, Antman EM, Charlesworth A, Cairns R, Murphy SA, de Lemos JA, Giugliano RP, McCabe CH, Braunwald E. TIMI risk score for ST-elevation myocardial infarction: A convenient, bedside, clinical score for risk assessment at presentation: An intravenous nPA for treatment of infarcting myocardium early II trial substudy. Circulation. 2000;102(17):2031-7.

25. Newson RB. Comparing the predictive powers of survival models using Harrell's C or Somers' D. Stata J. 2010;10(3):339-58.

26. Teunissen PFA, Tijssen $R$, van Montfoort ML, Robbers $L$, de Waard GA, van de Ven PM, Beek AM, Knaapen P, Meijers JCM, van Royen N. Kinetics of coagulation in ST-elevation myocardial infarction following successful primary percutaneous coronary intervention. Thromb Res. 2016;137:64-71.

27. Frangogiannis NG. Pathophysiology of myocardial infarction. Compr Physiol. 2015;5(4):1841-75.

28. Connolly SJ, Eikelboom JW, Bosch J, Dagenais G, Dyal L, Lanas F, Metsarinne K, O'Donnell M, Dans AL, Ha J-W, et al. Rivaroxaban with or without aspirin in patients with stable coronary artery disease: an international, randomised, double-blind, placebo-controlled trial. Lancet. 2018;391(10117):205-18.

29. Eikelboom J. Clopidogrel does not suppress blood markers of coagulation activation in aspirin-treated patients with non-ST-elevation acute coronary syndromes. Eur Heart J. 2002;23(22):1771-9.

30. Mahé I, Drouet L, Chassany O, Mazoyer E, Simoneau G, Knellwolf AL, Caulin C, Bergmann JF. D-dimer: a characteristic of the coagulation state of each patient with chronic atrial fibrillation. Thromb Res. 2002;107(1-2):1-6. 
31. Stefanadis C, Antoniou CK, Tsiachris D, Pietri P. Coronary atherosclerotic vulnerable plaque: current perspectives. J Am Heart Assoc. 2017;6:e005543. https://doi.org/10.1161/JAHA.117.005543.

32. Prisco D, Antonucci E, Fedi S, Margheri M, Giglioli C, Comeglio M, Lombardi A, Chioccioli M, Abbate R, Gensini GF. D-dimer increase after percutaneous transluminal angioplasty and clinical recurrence after primary revascularization in acute myocardial infarction? A pilot study. Clin Exp Med. 2001;1(4):219-24.

33. Gong X, Lei X, Huang Z, Song Y, Wang Q, Qian J, Ge J. D-dimer level predicts angiographic no-reflow phenomenon after percutaneous coronary intervention within 2-7 days of symptom onset in patients with STsegment elevation myocardial infarction. J Cardiovasc Transl Res. 2020 https://doi.org/10.1007/s12265-020-09991-6.

34. Zhang X, Wang S, Liu J, Wang Y, Cai H, Wang D, Fang S, Yu B. D-dimer and the incidence of heart failure and mortality after acute myocardial infarction. Heart. 2020;107(3):237-44. https://doi.org/10.1136/heartjnl-2020-316880.

35. Zhou J, Tan Y, Liu C, Zhou P, Sheng Z, Li J, Chen R, Zhao H, Song L, Yan H. Ticagrelor versus clopidogrel in patients with late or very late stent thrombosis. Cardiovasc Drug Ther. 2020;34(5):677-84.

36. Mega JL, Braunwald E, Wiviott SD, Bassand JP, Bhatt DL, Bode C, Burton P. Cohen M, Cook-Bruns N, Fox KA, et al. Rivaroxaban in patients with a recent acute coronary syndrome. N Engl J Med. 2012;366(1):9-19.

37. Mehta SR, Wood DA, Storey RF, Mehran R, Bainey KR, Nguyen H, Meeks B, Di Pasquale G, López-Sendón J, Faxon DP, et al. Complete revascularization with multivessel PCl for myocardial infarction. N Engl J Med. 2019;381(15):1411-21.

38. Bai XF, Zhang YP, Zhou J, Wu Y, Li RF, Sun LZ, Ma QQ, Lou BW, Zhai BW, Liu $M P$, et al. Combination of the CYP2C19 metabolizer and the GRACE risk score better predicts the long-term major adverse cardiac events in acute coronary syndrome undergoing percutaneous coronary intervention. Thromb Res. 2018;170:142-7.

39. Xanthakis V, Enserro DM, Murabito JM, Polak JF, Wollert KC, Januzzi JL, Wang TJ, Tofler G, Vasan RS. Ideal cardiovascular health: associations with biomarkers and subclinical disease and impact on incidence of cardiovascular disease in the Framingham Offspring Study. Circulation. 2014;130(19):1676-83.

40. Agorasti A, Trivellas T, Mourvati E, Papadopoulos V, Tsatalas K, Vargemezis V, Passadakis P. D-dimer, factor VIII and von Willebrand factor predict a nondipping pattern of blood pressure in hypertensive patients. Int Urol Nephrol. 2013;45(3):777-83.

41. Konieczynska M, Fil K, Bazanek M, Undas A. Prolonged duration of type 2 diabetes is associated with increased thrombin generation, prothrombotic fibrin clot phenotype and impaired fibrinolysis. Thromb Haemost. 2014; 111(4):685-93.

\section{Publisher's Note}

Springer Nature remains neutral with regard to jurisdictional claims in published maps and institutional affiliations.

Ready to submit your research? Choose BMC and benefit from:

- fast, convenient online submission

- thorough peer review by experienced researchers in your field

- rapid publication on acceptance

- support for research data, including large and complex data types

- gold Open Access which fosters wider collaboration and increased citations

- maximum visibility for your research: over $100 \mathrm{M}$ website views per year

At $\mathrm{BMC}$, research is always in progress.

Learn more biomedcentral.com/submissions 